an attempt to avoid decision making, but, particularly where interventions are costly or may have adverse consequences, clarity of evidence is essential. Prevention of iron deficiency is difficult. In spite of the high bioavailablity of iron in breast milk, both breastfed and bottle fed infants are at risk of developing iron deficiency unless sufficient iron is provided by the weaning diet. Dietary advice may not be effective in preventing iron deficiency anaemia, ${ }^{6}$ and the administration of elemental iron may have side effects. ${ }^{7}$ Large trials of both iron supplementation in infants and iron treatment in children with iron deficiency anaemia are urgently needed.
1 DeMayer E, Adiels-Tegman M. The prevalence of anaemia in the world. World Health Stat Quart 1985;38:302-16.

2 Moffatt MEK, Longstaffe S, Besant J, Dureski C. Prevention of iron deficiency and psychomotor decline in high-risk infants through the use of iron-fortified infant formula: a randomised clinical trial. I Pediatr 1994;125:527-34.

3 Lozoff B, De Andraca I, Walter T, Pino P. Does preventing iron deficiency anemia improve developmental test scores? Pediatr Res 1996;39:136A.

4 Idjradinata, P, Pollitt E. Reversal of developmental delays in iron-deficient anaemic infants treated with iron. Lancet 1993;341:14.

5 Aukett MA, Parks YA, Scott PH, Wharton BA. Treatment with iron increases weight gain and psychomotor development. Arch Dis Child 1986;61:849-57.

6 Childs F, Aukett A, Darbyshire P, Ilett S, Livera LM. Dietary education and iron deficiency anaemia in the inner city. Arch Dis Child 1997;76:144-7.

7 Idjradinata P, Watkins WE, Pollitt E. Adverse effects of iron supplementation on weight gain of iron-replete young children. Lancet 1994;343: $1252-4$.

\title{
Genetic determination of islet cell autoimmunity in monozygotic twin, dizygotic twin, and non-twin siblings of patients with type 1 diabetes: prospective twin study
}

\author{
Maria J Redondo, Marian Rewers, Liping Yu, Satish Garg, Colleen C Pilcher, Robert B Elliott, \\ George S Eisenbarth
}

\section{Barbara Davis \\ Center for \\ Childhood \\ Diabetes, University \\ of Colorado Health \\ Sciences Center, \\ Box B 140, Denver, \\ CL 80262, USA \\ Maria J Redondo, \\ postdoctoral fellow \\ Marian Rewers, \\ associate professor \\ Liping Yu, \\ research associate \\ Satish Garg, \\ associate professor \\ George S \\ Eisenbarth, \\ professor \\ Department of \\ Paediatrics, \\ University of \\ Auckland School of \\ Medicine, \\ New Zealand \\ Colleen C Pilcher, \\ technical officer \\ Robert B Elliott, \\ professor \\ Correspondence to: \\ Professor \\ Eisenbarth \\ george.eisenbarth@ \\ UCHSC.edu}

BMJ 1999;318:698-702

\begin{abstract}
Objective To test the hypothesis that non-diabetic dizygotic and monozygotic twin siblings of patients with type 1 diabetes have a similar high prevalence of islet cell autoantibodies, thus suggesting that islet cell autoimmunity is mainly environmentally determined.

Design Prospective twin study.

Setting Two specialist centres for diabetes in the United States.

Participants Non-diabetic monozygotic twin $(\mathrm{n}=53)$, dizygotic twin $(\mathrm{n}=30)$, and non-twin $(\mathrm{n}=149)$ siblings of patients with type 1 diabetes; 101 controls.

Main outcome measures Analysis of progression to diabetes and expression of anti-islet autoantibodies. Results Monozygotic twin siblings had a higher risk of progression to diabetes $(12 / 53)$ than dizygotic twin siblings $(0 / 30 ; \mathrm{P}<0.005)$. At the last follow up 22 $(41.5 \%)$ monozygotic twin siblings expressed autoantibodies compared with $6(20 \%)$ dizygotic twin siblings $(\mathrm{P}<0.05), 16(10.7 \%)$ non-twin siblings $(\mathrm{P}<0.0001)$, and $6(5.9 \%)$ controls $(\mathrm{P}<0.0001)$. Monozygotic twin siblings expressed multiple ( $\geqslant 2)$ antibodies more often than dizygotic twin siblings $(10 / 38$ v $1 / 23 ; \mathrm{P}<0.05)$. By life table analysis the probability of developing positive autoantibodies was higher among the monozygotic twin siblings bearing the diabetes associated HLA DQ8/DQ2 genotype than in those without this genotype $(64.2 \%$ (95\% confidence interval $32.5 \%$ to $96 \%$ ) $v 23.5 \%$ ( $7 \%$ to $40 \%)$ at 10 years of discordance; $\mathrm{P}<0.05)$.

Conclusion Monozygotic and dizygotic twins differ in progression to diabetes and expression of islet cell autoantibodies. Dizygotic twin siblings are similar to non-twin siblings. These two observations suggest that genetic factors play an important part in determination of islet cell autoimmunity, thus rejecting the hypothesis. In addition, there is a high
\end{abstract}

penetrance of islet cell autoimmunity in DQ8/DQ2 monozygotic twin siblings.

\section{Introduction}

Twin studies have contributed to our understanding of type 1 and type 2 diabetes mellitus. ${ }^{12-7}$ Nevertheless, limitations of twin studies include small sample sizes and the potential for biased overascertainment of concordant twin pairs. ${ }^{89}$ Such overascertainment is being dealt with by analysing twins identified through national registries ${ }^{67}$ and by the prospective study of twin pairs discordant for diabetes at recruitment. ${ }^{1-9}$

Over the past decade a series of islet autoantigens have been cloned ${ }^{10}$ and sensitive and specific autoantibody assays are now available. ${ }^{11}$ Non-diabetic monozygotic twin siblings of patients with type 1 diabetes show a high prevalence of islet cell autoantibodies in most studies, ranging between $42 \%$ and $76 \%{ }^{1}{ }^{712}$ This finding is concordant with their high progression to diabetes. Most autoantibodies determined by radioassays are consistently expressed before diabetes develops, and most monozygotic twin siblings with multiple autoantibodies develop diabetes in the long term. ${ }^{12}$

Studies of dizygotic twins from all series, even with life table projections, indicate a low concordance rate for diabetes, between $0 \%{ }^{12}$ and $13 \%,{ }^{5}{ }^{6}$ compared with $21 \%$ to $70 \%$ for monozygotic twins. ${ }^{156} 12$ The highest rates for progression to diabetes in monozygotic twin siblings have been reported in studies with life table analysis and long term follow up. ${ }^{17}$

A recent report concerning Danish dizygotic twins indicates that as many as $77 \%$ of non-diabetic dizygotic twin siblings expressed GAD65, insulin, or cytoplasmic islet cell autoantibodies. The results of this study are surprising in that they suggest that the expression of islet cell autoantibodies is environmentally determined 
Terms used in the paper

- Index or proband twin: in a pair, the twin who first developed the disease

- Discordance time: time from onset of disease in the index twin to onset of disease in the non-index twin or, if progression to disease did not occur, to the end of the study

- Islet cell antibodies: antibodies relevant for type 1 diabetes (for example, insulin, glutamic acid decarboxylase (GAD65), ICA512, and cytoplasmic islet cell antibodies)

- DR and DQ: HLA molecules associated with risk for type 1 diabetes. DR molecules are made up of two chains, $\mathrm{DR} \alpha$ and $\mathrm{DR} \beta$, but only $\mathrm{DR} \beta$ is polymorphic and needs to be specified. DQ molecules are made up of two polymorphic chains, $\mathrm{DQ} \alpha$ and $\mathrm{DQ} \beta$. Each unique polymorphic chain is designated by a number, DR by one (for example, DRB $1 * 0401$ ) and DQ by two (for example, DQA $1 * 0301$, DQB $1 * 0302$, also termed DQ8)

and that dizygotic twins who express islet cell autoantibodies are at a much lower risk of developing diabetes than non-twin siblings.?

Stimulated by this report we assembled a series of dizygotic twins to compare with our studies of monozygotic twins. ${ }^{1-4}$ We examined the prevalence of islet cell autoantibodies in non-diabetic dizygotic twin siblings and the prevalence of autoantibody expression and progression to diabetes in monozygotic twin siblings with the HLA genotype DQ8/DQ2.

\section{Participants and methods}

\section{Participants}

We evaluated 30 dizygotic and 53 monozygotic twin siblings of patients with type 1 diabetes. To avoid a biased overascertainment of concordant pairs we included only those siblings without diabetes at recruitment. The number of monozygotic twin siblings was larger than that of dizygotic twin siblings because recruitment of monozygotic twins started earlier. Table 1 summarises the monozygotic and dizygotic cohorts. Monozygosity was confirmed by parental report, same sex, HLA testing and blood group typing, and recently by DNA based testing for five highly polymorphic microsatellite loci (LDLR, GYPA, HBGG, D7S8, GC) (AmpliType PM, Perkin Elmer, Roche Molecular System, Branchburg, New Jersey). Out of those with available data on autoantibodies, $81.6 \%(31 / 38)$ of index monozygotic twins and $70 \%(7 / 10)$ of index dizygotic twins were positive for autoantibodies $(\geqslant 1)$.

Non-index twins were studied prospectively for progression to diabetes and, for those who developed diabetes, follow up ended at onset of disease. The median (range) follow up was $12.2(0-45.4)$ years for the monozygotic twin siblings and $5.9(0-22.6)$ years for the dizygotic twin siblings. Blood samples were sequentially drawn at follow up to be tested for islet cell autoantibodies. To determine the autoantibody status the last available serum sample was analysed. Samples drawn after the diagnosis of diabetes were not analysed. Participants who transiently expressed autoantibodies were considered negative for autoantibodies. The selection criterion for autoantibody analysis was availability of serum.
Table 1 Characteristics of monozygotic and dizygotic twin siblings of patients with type 1 diabetes

\begin{tabular}{lcc} 
Detail & Monozygotic twins ( $\mathbf{n = 5 3 )}$ & Dizygotic twins ( $\mathbf{n = 3 0 )}$ \\
\hline Recruited at BDC:Joslin Clinic & $17: 36$ & $20: 10$ \\
\hline Sex distribution (index/non-index) & $26 \mathrm{M} / \mathrm{M}, 27 \mathrm{~F} / \mathrm{F}$ & $5 \mathrm{M} / \mathrm{M}, 9 \mathrm{~F} / \mathrm{F}, 6 \mathrm{M} / \mathrm{F}, 10 \mathrm{~F} / \mathrm{M}$ \\
\hline Median (range) discordance: & & \\
\hline At first visit & $1.9(0-28.2)$ & $1.9(0-14.8)$ \\
\hline At last antibody test & $7.6(0-44.7)$ & $2.5(0-14.8)$ \\
\hline Median (range) age (years): & $13.6(2.1-52.7)$ & $10.1(1.8-33.2)$ \\
\hline At first visit & $21.5(3-64.4)$ & $10.5(2.4-34.2)$ \\
\hline At last antibody test & 53 & 30 \\
\hline Non-index twins tested for ICA ${ }^{*}$ & 2 \\
\hline Non-index twins tested for "biochemical" autoantibodies†: & 5 \\
\hline No antibody & 1 & 0 \\
\hline One autoantibody & 10 & 23 \\
\hline Two autoantibodies & 4 & \\
\hline Three autoantibodies & 38 & \\
\hline${ }^{*}$ Cytoplasmic islet cell autoantibodies. & & \\
\hline
\end{tabular}

*Cytoplasmic islet cell autoantibodies.

†Insulin, GAD65, and ICA512 autoantibodies.

The sibling group consisted of 149 non-twin siblings of patients with type 1 diabetes who were recruited as part of the diabetes autoimmunity study in the young (DAISY). ${ }^{13}$ The median (range) age at the first and last visit was, respectively, $3.3(0.5-7.9)$ and 5.1 $(0.7-11)$ years. The median follow up time was $2(0-4.1)$ years. In addition, 101 control participants (median age 30 (18.5-61) years) were tested. Studies were conducted with informed consent and approval from the Institutional Review Boards of the University of Colorado and the Joslin Diabetes Center.

\section{Islet cell autoantibody assays}

Serum samples were stored at $-20^{\circ} \mathrm{C}$ before testing. Insulin autoantibodies were measured by a fluid phase radioimmunoassay, incorporating competition with unlabelled insulin and precipitation with polyethylene glycol. $^{14}$ The assay uses $600 \mu \mathrm{l}$ of serum $(150 \mu \mathrm{l}$ duplicates with and without unlabelled insulin). The interassay coefficient of variation was $10.3 \%(n=7)$. The normal upper limit for insulin autoantibodies (42 $\mathrm{nU} / \mathrm{ml}$ ) was determined as the 99th centile of 198 healthy subjects without a first degree relative with diabetes. GAD65 autoantibodies were measured in duplicate by using the radioassay described by Falorni et $\mathrm{al}^{15}{ }^{16}$ This assay uses in vitro synthesised recombinant human GAD65 and precipitation with protein A Sepharose and scintillation counting. The results are expressed as an index calculated from the sample and control counts (index $=(\mathrm{cpm}$ patient sera-cpm control sera) $/(\mathrm{cpm}$ positive control sera-cpm control sera), where cpm is counts per minute. The interassay coefficient of variation was $6.5 \%$ $(\mathrm{n}=6)$. ICA512/IA-2 autoantibodies were measured by using a recombinant human ICA512 protein transcribed and translated in vitro with methionine labelled with sulphur-35. ${ }^{16}{ }^{17}$ The assay used clone ICA512bdc. ${ }^{18}$ The results are expressed as an index calculated with the same formula used in the GAD65 radioassay. The interassay coefficient of variation was $9.6 \%(\mathrm{n}=12)$. GAD65 and ICA5 12 were measured in a combined assay with a Packard Top $\beta$ counter with protein A sepharose and 96 well filtration. The 99th centile of GAD65 (index of 0.032) and ICA512 (index of 0.049) were established in 198 healthy control individuals. Cytoplasmic islet cell autoantibodies were 


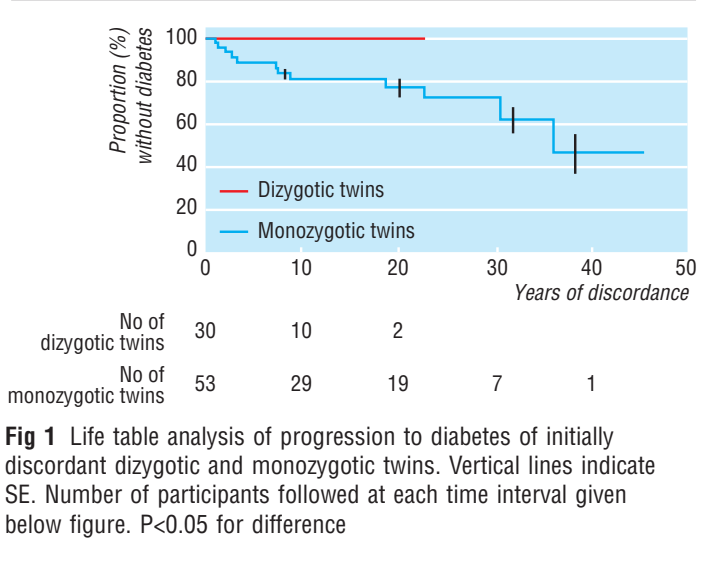

measured by indirect immunofluorescence with human pancreas as substrate by the laboratory of RBE, in New Zealand, as previously described. ${ }^{19}$

Assay sensitivity (in participants under 30 years of age) and specificity for each antibody assay evaluated in the Combinatorial Islet Autoantibody Workshop ${ }^{11}$ were, respectively, $58.1 \%$ and $98 \%$ for insulin, $83.7 \%$ and $99 \%$ for GAD65, $74.4 \%$ and $100 \%$ for ICA 152 , and $91.4 \%$ and $97 \%$ for cytoplasmic islet cell antibodies. The combinatorial sensitivity and specificity for expressing one or more positive autoantibodies are $97.7 \%$ and $94.1 \%$, respectively.

\section{HLA typing}

$\mathrm{DQ} \beta$ typing was performed with oligonucleotide probes as previously reported ${ }^{20}$ and $\mathrm{DQ} \alpha$ typing with

Table 2 Numbers (percentages) of participants positive for islet cell autoantibodies according to analysis of last serum sample before end of study or before progression to diabetes (if applicable)

\begin{tabular}{|c|c|c|c|c|}
\hline \multirow[b]{2}{*}{ Autoantibody } & \multicolumn{2}{|c|}{ Non-index twin siblings } & \multirow{2}{*}{$\begin{array}{l}\text { Non-twin } \\
\text { siblings }\end{array}$} & \multirow[b]{2}{*}{ Controls } \\
\hline & Monozygotic & Dizygotic & & \\
\hline Cytoplasmic islet cell & $18 / 53(34)$ & $3 / 10(10)$ & $6 / 47(13)$ & $3 / 101(3)$ \\
\hline Insulin & $13 / 52(25)$ & $2 / 28(7)$ & $13 / 149(9)$ & $2 / 101(2)$ \\
\hline GAD65 & $14 / 38(37)$ & $3 / 23(13)$ & $12 / 149(8)$ & $1 / 101(1)$ \\
\hline ICA512 & $6 / 42(14)$ & $1 / 23(4)$ & $9 / 149(6)$ & $0 / 101$ \\
\hline
\end{tabular}

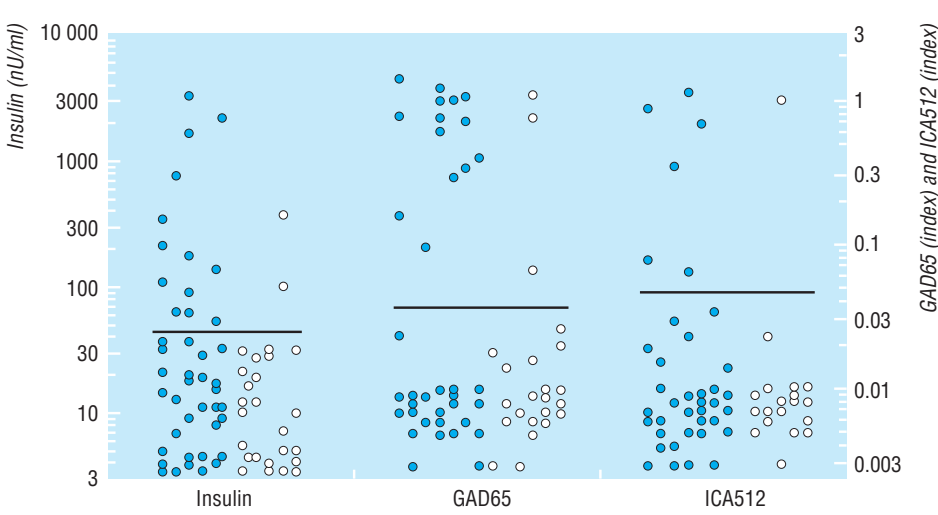

Fig 2 Dot plot of levels of autoantibodies in non-index monozygotic and dizygotic twins according to last serum samples before end of study or before progression to diabetes (if applicable). Y axis on left plots insulin concentration on log scale and on right plots GAD65 and ICA512 (index units) on log scale. Horizontal bars represent normal upper limit at 99th centile for each autoantibody. See table 2 for number of participants for whom each antibody was measured. Closed circles=monozygotic twins; open circles=dizygotic twins
AmpliType (PE Applied Biosystems, Branchburg, New Jersey).

\section{Statistical analysis}

Survival curves were estimated by the Kaplan-Meier method and compared by the log rank test (Prism, GraphPad Software, San Diego). Other statistical analysis included two sided $\chi^{2}$ and Fisher's exact tests.

\section{Results}

Twelve out of $53(22.6 \%)$ non-index monozygotic twin siblings developed diabetes during follow up. By life table analysis the probability of progression to diabetes was $18.6 \%$ (95\% confidence interval $6.9 \%$ to $30.4 \%)$ at 10 years of discordance and $22.7 \%(9.1 \%$ to $36.3 \%)$ at 20 years (fig 1). The median (range) age at diagnosis for the 12 who developed diabetes was 20.7 (4.1-49.9) years and the median discordance was 7.4 (1-36) years. Nine were men and three were women. None of the 30 dizygotic twins have yet developed diabetes (fig 1). Three out of 149 non-twin siblings (2\%) developed diabetes during follow up.

The prevalence of $\geqslant 1$ autoantibodies to insulin, GAD65, ICA512, and cytoplasmic islet cells was higher in non-index monozygotic twins $(22 / 53)$ than in non-index dizygotic twins $(6 / 30 ; \mathrm{P}<0.05)$, non-twin siblings $(16 / 149 ; \mathrm{P}<0.0001)$, and controls $(6 / 101$; $\mathrm{P}<0.0001)$. Insulin, GAD65, and cytoplasmic islet cell antibodies were each significantly more often expressed in monozygotic twins compared with siblings, while dizygotic twins did not differ significantly (table 2). Thirty eight monozygotic and 23 dizygotic twins were tested for all three biochemical autoantibodies (insulin, GAD65, and ICA512), and $26.3 \% \quad(10 / 38)$ and $4.3 \% \quad(1 / 23)$, respectively, expressed multiple $(\geqslant 2)$ autoantibodies $(\mathrm{P}<0.05)$. Figure 2 illustrates the levels of autoantibodies for non-index dizygotic and monozygotic twins.

Out of 12 monozygotic twin siblings who developed diabetes during follow up, 11 consistently expressed islet cell autoantibodies $(\geqslant 1)$ before or at diagnosis of diabetes. Multiple $(\geqslant 2)$ biochemical autoantibodies were present in four out of the seven twin siblings who developed diabetes and were tested for all three autoantibodies. The one patient who developed diabetes but had negative results for antibodies in his last test had previously expressed insulin antibodies but become negative before developing diabetes. All three non-twin siblings who developed diabetes were positive for autoantibodies before onset of the disease.

Forty two monozygotic and 28 dizygotic twins were recruited within 10 years after diagnosis of diabetes in the index twin. More monozygotic twin siblings were positive for $\geqslant 1$ autoantibodies than dizygotic twin siblings $(19 / 42 v 6 / 28 ; \mathrm{P}<0.05)$. Nine out of 30 monozygotic compared with one out of 21 dizygotic twin siblings $(\mathrm{P}<0.05)$ tested for all three biochemical autoantibodies were positive for $\geqslant 2$ autoantibodies.

Within 10 years of discordance, 17/42 (40.5\%) and $8 / 42(19 \%)$ monozygotic twin siblings developed diabetes or became positive for autoantibodies, respectively, compared with $0 / 28$ and 4/28 (14.3\%) dizygotic twins $(\mathrm{P}<0.05)$. Twenty nine monozygotic twins were followed up for longer than 10 years after onset of 
Table 3 Numbers (percentages) of dizygotic twins positive for each autoantibody according to last available serum sample

\begin{tabular}{lcc} 
Autoantibody & Danish series* & BDC/Joslin series \\
\hline Cytoplasmic islet cell & $9 / 35(26)$ & $3 / 30(10)$ \\
\hline Insulin & $17 / 35(49)$ & $2 / 28(7.1) \dagger$ \\
\hline GAD65 & $14 / 35(40)$ & $3 / 23(13) \dagger$ \\
\hline${ }^{*}$ ICA512 not reported. & & \\
†P<0.005. & &
\end{tabular}

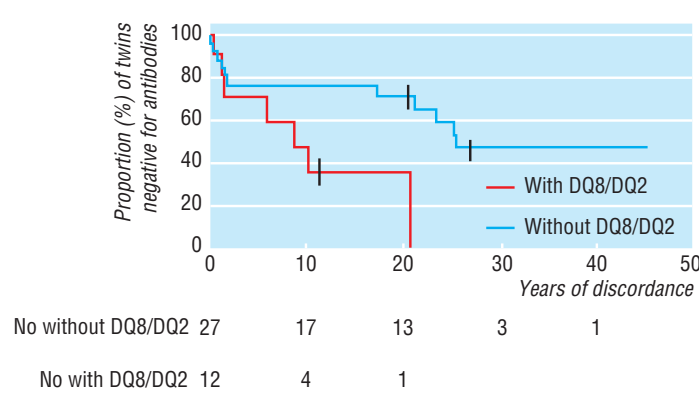

Fig 3 Life table analysis of progression to positive autoantibodies in non-index monozygotic twins. Subjects with and without HLA DQ8/DQ2 compared. Years of discordance indicates time from onset of diabetes in index twin. $P=0.02$ for difference

diabetes in the index twin. Ten of them were positive for autoantibodies or progressed to diabetes. Among the 24 monozygotic twins followed up for 10 years or less follow up ended in 13 participants because of progression to diabetes. In the cohort of dizygotic twins followed for over 10 years three out of 10 were positive for autoantibodies.

By life table analysis the probability of developing positive autoantibodies was higher for the monozygotic twins bearing HLA DQ8/DQ2 than for the monozygotic twins without this genotype $(\mathrm{P}<0.05)$ (fig 3). In this analysis the time to the first serum sample that tested consistently positive for $\geqslant 1$ autoantibodies was used to date conversion to positivity. Only participants with known DQ8/DQ2 $(n=39)$ were included. After 10 years of discordance the probability of developing positive autoantibodies for monozygotic twins with and without DQ8/DQ2 was $64.2 \% \quad(95 \%$ confidence interval $32.5 \%$ to $96 \%$ ) and $23.5 \%$ (7\% to $40 \%)$, respectively $(\mathrm{P}<0.05)$.

\section{Discussion}

There is universal agreement that monozygotic twin siblings of patients with type 1 diabetes have a higher risk of developing diabetes compared with dizygotic twin siblings of patients with diabetes. The survival curves obtained for our cohorts of monozygotic and dizygotic twins are significantly different $(\mathrm{P}<0.05$; fig 1 ), and our observed progression to diabetes is consistent with that reported previously. ${ }^{156}{ }^{12}$ In our series the probability of monozygotic twins becoming concordant for diabetes was $13.5 \%$ (95\% confidence interval $3.4 \%$ to $23.5 \%$ ) at 7 years of discordance and $22.7 \%$ $(9.1 \%$ to $36.3 \%)$ at 20 years. These may be underestimates of the actual rate of concordance as those twin pairs already concordant at recruitment were not included in the study. The absence of progression to diabetes to date in dizygotic twins is not
Key messages

- Monozygotic twin siblings of patients with type 1 diabetes have a higher risk of progression to diabetes and of expressing islet cell antibodies than dizygotic twin and non-twin siblings

- Monozygotic twins with the HLA genotype DQ8/DQ2 have a high risk of expression of islet cell autoimmunity and progression to diabetes

- Islet cell autoimmunity seems to be predominantly genetically determined

significantly different from the progression in non-twin siblings in our or other ${ }^{21}$ series. The higher concordance rate in monozygotic twins than in dizygotic twins suggests the importance of genetic factors in the aetiology of type 1 diabetes. The fact that the concordance rate in monozygotic twins is not $100 \%$ implies that environmental factors also play a part.

In Denmark Petersen and coworkers reported that $77 \%(27 / 35)$ of dizygotic twins without diabetes expressed at least one islet cell antibody. ${ }^{7}$ In contrast, in our series only $20 \%(6 / 30)$ of such twins were positive for $\geqslant 1$ antibodies (table 3). Dizygotic twins did not express autoantibodies more often than siblings of patients with type 1 diabetes $(6 / 30 v 16 / 149 ; \mathrm{P}=0.21)$.

It is unlikely that dizygotic twins in Denmark differ fundamentally from those in the United States. The twin pairs of our series were ascertained between 1970 and 1997, at a time when the incidence of diabetes in the United States was about 15/100 000 person years. The Danish Twin Register was established in $1991^{22}{ }^{23}$; between 1989 and 1993 the incidence of type 1 diabetes in Denmark was 17.4 per 100000 person years. ${ }^{23}$

We believe that the most likely explanation for the different results between the two studies relates to differences in the assays used for detection of islet cell autoantibodies. Marked differences between laboratories in specificity and sensitivity of such assays have been described. ${ }^{11}$ Differences within laboratories may also occur over time. The concordance for insulin autoantibodies between different laboratories was considerably lower than for ICA512 and GAD65 autoantibodies, as tested in the Combinatorial Islet Autoantibody Workshop. ${ }^{11}$

Johnston et al reported that monozygotic twins with HLA DR3/DR4 had higher concordance for type 1 diabetes than monozygotic twins without this genotype. ${ }^{24}$ In our study monozygotic twins with HLA DQ8/DQ2, which is associated with diabetes, usually in linkage disequilibrium with DR3/4, had a higher risk of progression to islet cell autoimmunity and diabetes (fig 3). This finding further supports the hypothesis that islet cell autoimmunity may be predominantly genetically determined.

It will be important to analyse additional series of dizygotic twins and to continue prospective studies of the twin series already reported. A paradigm shift will occur if dizygotic twins have a similar prevalence of autoantibody expression to monozygotic twins. We believe that at this time such paradigm shift is not warranted. 
We thank Terry Smith, research nurse, who has implemented twin studies for more than three decades, and Jules Amer for his valuable suggestions.

Contributors: GSE studied monozygotic twins at the Joslin Clinic (Boston, Massachusetts) and at the Barbara Davis Center (Denver, Colorado). GSE, the principal investigator, formulated the hypothesis and is the guarantor for the paper. MJR organised the study and contributed to the genetic analyses. MR is the principal investigator in the DAISY study. LY carried out islet cell autoantibody analysis. SG contributed to clinical follow up and referral of the twins. RBE and CCP carried out cytoplasmic islet cell antibodies assay. The paper was written by MJR and GSE.

Funding: National Institutes of Health Grants DK 32083-16, American Diabetes Foundation, and Children's Diabetes Foundation. MJR was supported by the Fondo de Investigación Sanitaria (F.I.S. 97/5094). MR was supported by the National Institutes of Health Grant 5 R01 DK 32493 and CRC 509.

Competing interests: None declared.

1 Verge CF, Gianani R, Yu L, Pietropaolo M, Smith T, Jackson RA, et al. Late progression to diabetes and evidence for chronic $\beta$ cell autoimmunity in progression to diabetes and evidence for chronic $\beta$ cell autoimmunity in

2 Dib S, Vardi P, Connelly J, Eisenbarth GS, Soeldner JS. Immune changes associated with insulin dependent diabetes may remit without causing the disease: a study in identical twins. BMJ 1986;292:1670.

3 Srikanta S, Ganda OP, Eisenbarth GS, Soeldner JS. Islet cell antibodies and $\beta$ cell function in monozygotic triplets and twins initially discordant for type I diabetes mellitus. N Engl J Med 1983;308:322-5.

4 Srikanta S, Ganda OP, Jackson RA, Gleason RE, Kaldany A, Gorovoy MR, et al. Type I diabetes mellitus in monozygotic twins: chronic progressive beta cell dysfunction. Ann Intern Med 1983:99:320-6.

5 Kumar D, Gemayel NS, Deapen D, Kapadia D, Yamashita PH, Lee M, et al. North-American twins with IDDM: genetic, etiological, and clinical significance of disease concordance according to age, zygosity, and the interval after diagnosis in first twin. Diabetes 1993;42:1351-63.

6 Kyvik KO, Green A, Beck-Nielsen H. Concordance rates of insulin dependent diabetes mellitus: a population based study of young Danish twins. BMJ 1995;311:913-7.

7 Petersen JS, Kyvik KO, Bingley PJ, Gale EAM, Green A, Dryberg T, et al. Population based study of prevalence of islet cell autoantibodies in monozygotic and dizygotic Danish twin pairs with insulin dependent diabetes mellitus. BMJ 1997;314:1575-9.

8 Hawkes CH. Twin studies in diabetes mellitus. Diabet Med 1997;17:34752.

9 Rowe RE, Leslie RDG. Twin studies in insulin-dependent diabetes and other autoimmune diseases. Diabetes Metab Rev 1995;11:121-36
10 Atkinson MA, Maclaren NK. Islet cell autoantigens in insulin dependent diabetes. J Clin Invest 1993;92:1608-16.

11 Verge CF, Stenger D, Bonifacio E, Colman PG, Pilcher C, Bingley PJ, et al. Combined use of autoantibodies (IA-2ab, Gadab, IAA, ICA) in type 1 diabetes: combinatorial islet autoantibody workshop. Diabetes 1998:47:1857-66.

12 Hawa M, Rowe R, Lan MS, Notkins AL, Pozzilli P, Christie MR, et al. Value of antibodies to islet protein tyrosine phosphatase-like molecule in predicting type 1 diabetes. Diabetes 1997;46:1270-5.

13 Rewers M, Bugawan TL, Norris JM, Blair A, Beaty B, Hoffman M, et al. Newborn screening for HLA markers associated with IDDM: diabetes autoimmunity study in the young (DAISY). Diabetologia 1996;39:807-12.

14 Ziegler AG, Ziegler R, Vardi P, Jackson RA, Soeldner JS, Eisenbarth GS. Life table analysis of progression to diabetes of anti-insulin autoantibodypositive relatives of individuals with type I diabetes. Diabetes 1989;38:1320-5.

15 Falorni A, Örtqvist E, Persson B, Lernmark L. Radioimmunoassays for glutamic acid decarboxylase (GAD65) and GAD65 autoantibodies using ${ }^{35} \mathrm{~S}$ or ${ }^{3} \mathrm{H}$ recombinant human ligands. J Immunol Methods 1995;186:8999.

16 Verge CF, Gianani R, Kawasaki E, Yu L, Pietropaolo M, Jackson RA, et al. Prediction of type I diabetes in first-degree relatives using a combination of insulin, GAD, and ICA512bdc/IA-2 autoantibodies. Diabetes 1996;45:926-33.

17 Gianani R, Rabin DU, Verge CF, Yu L, Babu S, Pietropaolo M, et al. ICA512 autoantibody radioassay. Diabetes 1995;44:1340-4.

18 Kawasaki E, Yu L, Gianani R, Verge CF, Babu S, Bonifacio E, et al. Evaluation of islet cell antigen (ICA) 512/IA-2 autoantibody radioassays using overlapping ICA512/IA-2 constructs. J Clin Endocrinol Metab 1997;82:375-80.

19 Pilcher CC, Elliott RB. A sensitive and reproducible method for the assay of human islet cell antibodies. J Immunol Methods 1990;129:111-7.

20 Bugawan TL, Erlich HA. Rapid typing of HLA-DQB1 DNA polymorphism using nonradioactive oligonucleotide probes and amplified DNA. Immunogenetics 1991;33:163-70.

21 Lorenzen T, Pociot F, Hougaard P, Nerup J. Long-term risk of IDDM in first-degree relatives of patients with IDDM. Diabetologia 1994:37:321-7.

22 Kyvik KO, Green A, Beck-Nielsen H. The most recent part of the Danish twin registry. Establishment and analysis of zygote specific twinning rates. Ugeskr Laeger 1996;158:3456-60.

23 Svendsen AJ, Kreutzfeld JC, Lund EB, Kyvik KO, Green A. Incidence of juvenile-onset diabetes in Denmark. A prospective registration in the counties of Fyn, Ribe, Sonderjylland and Vijlel. Ugeskr Laeger 1997;159:1257-60.

24 Johnston C, Pyke DA, Cudworth AG, Wolf E. HLA-DR typing in identical twins with insulin-dependent diabetes: difference between concordant and discordant pairs. BMJ 1983;286:253-5.

(Accepted 5 January 1999)

\title{
Training in large bowel cancer surgery: observations from three prospective regional United Kingdom audits
}

\author{
R J Aitken, M R Thompson, J A E Smith, A G Radcliffe, J D Stamatakis, R J C Steele
}

Editorial by Collins

Eastern General

Hospital, Edinburgh

EH6 7LN

RJ Aitken,

consultant surgeon

Queen Alexandra Hospital, Cosham

Portsmouth

PO6 3LY

M R Thompson,

consultant surgeon

Wessex Cancer

Intelligence Unit,

Highcroft, Romsey

Road, Winchester,

Hampshire

$\mathrm{SO} 225 \mathrm{DH}$

J A E Smith,

director

continued over

BMJ 1999;318:702-3
Operative experience under the supervision of a consultant must be at the core of any surgical training programme. Almost no objective data on general surgical training, however, exist in the United Kingdom. Colorectal cancer surgery represents a substantial part of general surgery; the operations are of differing complexity, and a third present as emergencies. Individual surgeons may influence outcome after colorectal cancer surgery. ${ }^{1}$ We determined trainee surgeons' supervised experience in three prospective UK colorectal cancer audits.

\section{Methods and results}

The audits covered 1990-4. The number of resections undertaken by trainees, and the proportion of these supervised by a consultant, were determined. A supervised resection was one in which the operation note named the consultant as the assistant. These audits did not record observational supervision. Right hemicolec- tomy and anterior resection for rectal and rectosigmoid cancers were considered to be representative of operations undertaken by junior and senior trainees. The current number of specialist registrar posts is 21 in Lothian and Borders, 50 in Wessex, and 125 in Trent and Wales.

Altogether, 7282 elective and 1594 emergency resections were performed (table); trainees performed $2772(39.8 \%)$ of the elective and $1089(65.2 \%)$ of the emergency resections. A consultant was present at $63.7 \%$ (5653) of all resections $(54.9 \%$ (4874) as the surgeon and $8.8 \%$ (779) as assistant to a trainee). Consultants supervised $20.2 \%(779 / 3861)$ of the resections performed by trainees.

Of the 2275 right hemicolectomies performed, trainees undertook $1300(57.1 \%)$, and a consultant assisted in $198(15.2 \%)$ of these. Of 1849 elective anterior resections performed for rectosigmoid and rectal cancers, trainees undertook 571 (30.9\%), and a consultant assisted in 197 (34.5\%) of these. 